\title{
Changes in population density of Pratylenchus neglectus (Rensch, 1924) in the soil with oilseed rape Brassica napus L. cultivation
}

\section{Zmiany zagęszczenia populacji Pratylenchus neglectus (Rensch, 1924) w glebie z uprawą rzepaku Brassica napus L.}

\author{
Renata Dobosz*
}

\begin{abstract}
Summary
Observations on the change of population density of Pratylenchus neglectus in soil with Brassica napus L. cultivation were performed in years 2010-2013. The experiment was performed outdoor in pots with naturally infected soil of 50 specimens per $200 \mathrm{~cm}^{3}$, in four replicates. Two cultivars of oilseed rape, spring (cultivar Bios) and winter (cultivar Poznaniak) were included in the studies. The control plant was wheat Triticium aestivum L., cultivar Narwa and cultivar Mewa, in spring and winter experiment, respectively. Population density of the nematode distinctly decreased in soil with cultivation of spring and winter oilseed rape. The value of $\mathrm{Pf} / \mathrm{Pi}=0.29-0.7$ was statistically lower than that of Triticium aestivum cropping (Pf/Pi $=1.03-1.32$ ).
\end{abstract}

Key words: Pratylenchus neglectus; Brassica napus; population density

\section{Streszczenie}

Obserwacje dynamiki populacji Pratylenchus neglectus w glebie z uprawą rzepaku Brassica napus L. przeprowadzono w latach 2010-2013. Badania wykonano $w$ warunkach zewnętrznych, w wazonach wypełnionych glebą naturalnie zasiedloną przez nicienie w zagęszczeniu 50 osobników $200 \mathrm{~cm}^{3}$ gleby, w czterech powtórzeniach. W doświadczeniach użyto zarówno formę jarą (odmiana Bios), jak i ozimą (odmiana Poznaniak) rzepaku. Rośliną kontrolną była pszenica: forma jara - odmiana Narwa oraz forma ozima odmiana Mewa. Zagęszczenie populacji nicienia obniżyło się zarówno w glebie z uprawą formy ozimej rzepaku, jak i formy jarej. Wskaźnik zmiany zagęszczenia Pf/Pi $=0,29-0,7$ był statystycznie istotnie niższy niż $\mathrm{w}$ uprawie porównawczej pszenicy Triticium aestivum $\mathrm{L}$. (Pf/Pi $=1,03-1,32)$.

Słowa kluczowe: Pratylenchus neglectus; Brassica napus; zagęszczenie populacji

Instytut Ochrony Roślin - Państwowy Instytut Badawczy

Władysława Węgorka 20, 60-318 Poznań

*corresponding author: r.dobosz@iorpib.poznan.pl 


\section{Wstęp / Introduction}

Oprócz soi Glycine max (L.) i słonecznika Helianthus annuus L., rzepak Brassica napus L. jest jednym z najważniejszych gatunków roślin oleistych uprawianych na świecie. Największymi producentami tej rośliny są Chiny, Kanada oraz Indie, gdzie produkcja osiąga odpowiednio 25, 20 i 14\% ogólnej uprawy rzepaku na świecie (FAO). Według Głównego Urzędu Statystycznego areał przeznaczony pod uprawę rzepaku w Polsce osiągnął w 2013 roku około $0,9 \mathrm{mln}$ ha i wzrósł $\mathrm{w}$ przybliżeniu o 25 procent w stosunku do powierzchni gruntów objętych uprawą tej rośliny w roku 2012 (www.stat.gov.pl). Rzepak jest rośliną o szerokim zastosowaniu wykorzystywaną w przemyśle spożywczym, do produkcji biopaliw, a także jako źródło wysokobiałkowych pasz w hodowli zwierząt.

Wszystkie gatunki rodzaju Pratylenchus Filipjev, 1936 są obligatoryjnymi pasożytami roślin, a w ich cyklu osobniczym wyodrębnia się sześć stadiów rozwojowych: stadium jaja, formy młodociane J2-J4 oraz formy dorosłe. Wszystkie stadia z wyjątkiem jaj posiadają zdolność ruchu, co umożliwia aktywne ich przemieszczanie się w glebie. Obserwacje długości cyklu rozwojowego $P$. penetrans (Cobb, 1917) (Mizukubo i Adachi 1997; Wu i wsp. 2002), P. coffae (Zimmermann, 1898) i P. loosi Loof, $1960(\mathrm{Wu}$ i wsp. 2002) oraz P. thornei Sher et Allen, 1953 (Castillo i wsp. 1995) i P. zeae Graham, 1951 (Meyer 1985), przeprowadzone $\mathrm{w}$ warunkach kontrolowanych pokazały, że czas trwania cyklu rozwojowego wynosi od 22 do 46 dni i zależy od wilgotności, temperatury, roślinyżywiciela i gatunku nicienia. Ponadto, również w warunkach laboratoryjnych, zaobserwowano, że wydzieliny korzeni kukurydzy wpływają na proces opuszczania jaj przez formy J2 P. zeae (De Waele i wsp. 1988).

Poza obszarem Antarktydy, występowanie korzeniaka pospolitego P. neglectus (Rensch, 1924) zostało odnotowane na wszystkich kontynentach. Gatunek ten znajdowany był w tkankach korzeni i w glebie otaczającej systemy korzeniowe zarówno roślin dziko rosnących, jak i uprawnych: zbóż, strączkowych, okopowych, truskawki oraz rzepaku (Wolny 1990; Castillo i Volvas 2007; Kumari 2012). Badania Wolnego (1990) wykazały, że P. neglectus wystąpił aż w 56\% prób zebranych z pól, na których uprawiano rzepak ozimy wykazujący objawy zahamowania wzrostu.

Niektóre gatunki i odmiany zbóż oraz roślin uprawnych $\mathrm{z}$ rodziny bobowatych Fabaceae Lindl. nie wpływają na poziom zagęszczenia populacji Pratylenchus spp. w glebie utrzymując liczebność na stałym poziomie, inne natomiast modyfikują zagęszczenie populacji korzeniaków prowadząc do wzrostu lub obniżenia liczebności populacji tych nicieni w glebie (Al-Rehiayani i Hafez 1998; Di Vito i wsp. 2000; Tylor i wsp. 2000; Ballard i wsp. 2006).

$\mathrm{Na}$ zagęszczenie populacji korzeniaków oddziałują również rośliny $\mathrm{z}$ rodziny krzyżowych Brassicaceae Burnett. $\mathrm{W}$ badaniach in vitro $\mathrm{z}$ użyciem rzepaku swoją liczebność zmniejszyły populacje $P$. crenatus Loof, 1960, P. thornei, P. fallax Seinhorst, 1968, P. penetrans oraz $P$. pinguicaudatus Corbett, 1969, przy czym rośliną porównawczą była wówczas kukurydza (Webb 1990, 1996). W doświadczeniu $\mathrm{z}$ uprawą rzepaku w kontro- lowanych warunkach szklarni zmniejszyła się liczebność populacji P. scribneri Steiner, 1943 (Bernard i Montgomery-Dee 1993), a uprawa rzepy Brassica rapa L. i gorczycy białej Sinapsis alba L. spowodowała wzrost zagęszczenia populacji $P$. penetrans (Talatschian 1974; Bélair i wsp. 2002). Zmalało natomiast zagęszczenie populacji $P$. neglectus $\mathrm{w}$ doświadczeniu in vitro, w którym użyto rzepaku (Webb 1996), a w kontrolowanych warunkach szklarni uprawa rzepaku, gorczycy białej oraz rzodkwi oleistej Raphanus sativus L. spowodowała wzrost liczebności populacji tego gatunku nicienia (Al-Rehiayani i Hafez 1998). Przedstawione powyżej wyniki badań w warunkach kontrolowanych sugerują, że rzepak może wpłynąć na zmianę wielkości populacji $P$. neglectus w glebie również $\mathrm{w}$ uprawie polowej.

Celem pracy była ocena i porównanie zmian zagęszczenia populacji $P$. neglectus $\mathrm{w}$ glebie $\mathrm{z}$ uprawą rzepa$\mathrm{ku} \mathrm{w}$ formie jarej i ozimej $\mathrm{w}$ trzech sezonach wegetacyjnych w warunkach naturalnych.

\section{Materiały i metody / Materials and methods}

Obserwacje wykonano w latach 2010-2013. Doświadczenie mające na celu określenie zagęszczenia populacji $P$. neglectus $\mathrm{w}$ glebie $\mathrm{z}$ uprawą rzepaku przeprowadzono w wazonach, w warunkach zewnętrznych. W doświadczeniu wykorzystano glebę naturalnie zakażoną nicieniem, którego populacja rozwijała się wcześniej na pszenicy. Ziemię dokładnie wymieszano, po czym określono początkowe zagęszczenie populacji nicienia (Pi) (50 osobników/200 $\mathrm{cm}^{3}$ gleby) stosując metodę wirówkową (Van Bezooijen 2006). Wazony o objętości 10 litrów wypełniono glebą, wkopano w ziemię i wysiano rzepak ozimy B. napus odmiana Poznaniak i rzepak jary B. napus odmiana Bios zgodnie z przyjętymi terminami agrotechnicznymi. Uprawą kontrolną w doświadczeniu była pszenica Triticium aestivum L. jara i ozima, odpowiednio odmiana Narwa oraz Mewa. Dla każdej rośliny wykonano cztery powtórzenia. Po zakończeniu wegetacji roślin określono końcowe zagęszczenie populacji nicienia $(\mathrm{Pf})$ również wykorzystując metodę wirówkową. Liczebności populacji nicienia określone po zakończeniu wegetacji roślin poddano analizie wariancji ANOVA, a różnice między średnimi oceniono testem Tukeya na poziomie istotności $\alpha=0,05$. Po zakończeniu wegetacji roślin wyliczono wskaźniki rozwoju populacji nicienia $(\mathrm{Pf} / \mathrm{Pi}) \mathrm{w}$ glebie $\mathrm{z}$ uprawą każdej $\mathrm{z}$ włączonych do badań odmian (Seinhorst 1970).

\section{Wyniki i dyskusja / Results and discussion}

Zagadnienie związku liczebności populacji nicieni pasożytów roślin występujących $\mathrm{w}$ glebie $\mathrm{z}$ uprawą roślin oleistych jest ważnym elementem badań nematologicznych. Rośliny te są bowiem ważne gospodarczo, a niektóre $\mathrm{z}$ nich wykorzystuje się również $\mathrm{w}$ międzyplonie, jako źródło naturalnego nawozu lub w celu ograniczenia rozwoju populacji nicieni (Piszczek i Mrówczyński 2012).

$\mathrm{Na}$ podstawie przeprowadzonych doświadczeń wykazano, że uprawa rzepaku spowodowała spadek liczebności 
Tabela 1.Zagęszczenia populacji Pratylenchus neglectus w glebie po zakończeniu wegetacji rzepaku i pszenicy oraz wyniki analizy testu Tukeya na poziomie istotności $\alpha=0,05$

Table 1. Final population density of Pratylenchus neglectus in soil after vegetation of oilseed rape and wheat and results of Tukey's test at $\alpha=0.05$

\begin{tabular}{|c|c|c|c|c|c|c|c|}
\hline \multirow{3}{*}{\multicolumn{2}{|c|}{$\begin{array}{c}\text { Roślina/odmiana } \\
\text { Plant/cultivar }\end{array}$}} & \multirow{2}{*}{\multicolumn{3}{|c|}{$\begin{array}{l}\text { Liczba osobników w } 200 \mathrm{~cm}^{3} \text { gleby } \\
\text { Number of specimens in } 200 \mathrm{~cm}^{3} \text { soil } \\
\text { rok - year }\end{array}$}} & \multicolumn{3}{|c|}{$\begin{array}{l}\text { Wartość wskaźnika rozwoju populacji } \mathrm{Pf} / \mathrm{Pi} \\
\text { Value of the ratio of population growth } \mathrm{Pf} / \mathrm{P}\end{array}$} \\
\hline & & & & & \multicolumn{3}{|c|}{ rok - year } \\
\hline & & $2010 / 2011$ & $2011 / 2012$ & $2012 / 2013$ & $2010 / 2011$ & $2011 / 2012$ & $2012 / 2013$ \\
\hline \multirow{2}{*}{$\begin{array}{l}\text { Forma } \\
\text { jara } \\
\text { Spring } \\
\text { crop }\end{array}$} & $\begin{array}{l}\text { Brassica napus } \\
\text { odmiana - cultivar } \\
\text { Bios }\end{array}$ & $23,3 \mathrm{~b}$ & $17,8 \mathrm{~b}$ & $14,3 \mathrm{~b}$ & 0,46 & 0,35 & 0,29 \\
\hline & $\begin{array}{l}\text { Triticium aestivum } \\
\text { odmiana - cultivar } \\
\text { Narwa }\end{array}$ & 56,2 a & $68,5 \mathrm{a}$ & $51,5 \mathrm{a}$ & 1,12 & 1,37 & 1,13 \\
\hline \multirow{2}{*}{$\begin{array}{l}\text { Forma } \\
\text { ozima } \\
\text { Winter } \\
\text { crop }\end{array}$} & $\begin{array}{c}\text { Brassica napus } \\
\text { odmiana - cultivar } \\
\text { Poznaniak }\end{array}$ & $25,5 \mathrm{~b}$ & $13,3 \mathrm{~b}$ & $12,5 \mathrm{~b}$ & 0,51 & 0,27 & 0,25 \\
\hline & $\begin{array}{c}\text { Triticium aestivum } \\
\text { odmiana - cultivar } \\
\text { Mewa }\end{array}$ & $60,8 \mathrm{a}$ & 56,8 a & $50,8 \mathrm{a}$ & 1,19 & 1,13 & 1,02 \\
\hline
\end{tabular}

Wartości oznaczone tą samą literą nie różnią się istotnie - Values marked with the same letter do not differ significantly

populacji $P$. neglectus $\mathrm{w}$ glebie $\mathrm{w}$ każdym $\mathrm{z}$ sezonów wegetacyjnych (tab. 1). Uprawa odmiany jarej rzepaku obniżyła zagęszczenie populacji korzeniaka o $54 \% \mathrm{w}$ pierwszym, o $65 \%$ w drugim i o $71 \%$ w trzecim sezonie obserwacji. Uprawa odmiany ozimej rzepaku spowodowała spadek liczebności populacji nicienia o 41, 73 i 75\% odpowiednio w pierwszym, drugim i trzecim roku prowadzenia doświadczenia. Zagęszczenia populacji $P$. neglectus po zakończeniu wegetacji obu odmian rzepaku nie różniły się istotnie między sobą. W każdym z sezonów wyniki uzyskane dla wariantów z użyciem rzepaku były istotnie statystycznie różne od tych uzyskanych dla pszenicy, w uprawie której zaobserwowano wzrost zagęszczenia populacji korzeniaka, maksymalnie o $35 \%$.

W przeprowadzonych badaniach uwzględniono zagęszczenie populacji $P$. neglectus, jakie obserwowano najczęściej na polach $\mathrm{z}$ uprawą roślin zbożowych w Wielkopolsce (Kornobis 1982). Doświadczenia pokazały, że populacja korzeniaka o zagęszczeniu 50 osobników przypadających na $200 \mathrm{~cm}^{3}$ gleby nie zwiększa swego zagęszczenia po zakończeniu wegetacji roślin. Trudno zatem sugerować bezpośrednią szkodliwość tego gatunku nicienia $\mathrm{w}$ uprawie rzepaku ozimego mimo, że populacje $P$. neglectus izolowano $\mathrm{z}$ gleby stowarzyszonej z zahamowaniem wzrostu rzepaku aż z 56\% badanych prób (Wolny 1990). Wyniki prowadzonych równolegle obserwacji cyklu rozwojowego $P$. neglectus wskazują, iż rzepak nie jest dobrą rośliną żywicielską dla nicienia, gdyż około $70 \%$ osobników znajdowano w glebie otaczającej korzenie roślin (Dobosz, dane niepublikowane). Niską atrakcyjność pokarmową rzepaku tłumaczą Porter i wsp. (1999), według których wynika ona $\mathrm{z}$ poziomu obecnych w tkankach glukozynolanów i maleje wraz ze wzrostem poziomu tych związków.

Wyniki badań dostępne w literaturze oraz wyniki uzyskane $\mathrm{w}$ doświadczeniach opisanych powyżej wskazują, że na związek między uprawą gatunków roślin krzyżowych a zagęszczeniem populacji Pratylenchus spp. w glebie ma wpływ działanie co najmniej kilka czynników, do których zalicza się gatunek rośliny, a także warunki doświadczenia oraz gatunek nicienia i wielkość jego populacji.

\section{Wnioski / Conclusions}

1. Rzepak nie jest dobrą rośliną żywicielską dla $P$. neglectus. Uprawa zarówno formy jarej, jak i ozimej tej rośliny powoduje spadek zagęszczenia populacji nicienia w glebie.

2. Populacje $P$. neglectus o liczebności 50 osobników w $200 \mathrm{~cm}^{3}$ gleby nie stanowią zagrożenia dla uprawy rzepaku.

\section{Literatura / References}

Al-Rehiayani S., Hafez S. 1998. Host status and green manure effect of selected crops on Meloidogyne chitwoodi race 2 and Pratylenchus neglectus. Nematropica 28 (2): 213-230.

Ballard R.A., Hulton R.E., Taylor S.P., McKay A.C., Howie J.H. 2006. Field resistance of annual pasture legumes to the root lesion nematode Pratylenchus neglectus. Australasian Plant Pathology 35 (3): 303-308.

Bernard E.C., Montgomery-Dee M.E. 1993. Reproduction of plant-parasitic nematodes on winter rapeseed (Brassica napus ssp. oleifera). Journal of Nematology 25 (4S): 863-868. 
Bélair G., Fournier Y., Dauphinais N., Dang O.P. 2002. Reproduction of Pratylenchus penetrans on various rotation crops in Quebec. Phytoprotection 83: 111-114.

Castillo P., Jimenez Diaz R.M., Gomez-Barcina A., Volvas N. 1995. Parasitism of the root-lession nematode Pratylenchus thornei on chipea. Plant Pathology 44: 728-733.

Castillo P., Volvas N. 2007. Pratylenchus (Nematoda: Pratylenchidae): Diagnosis, Biology, Pathogenicity and Management. Nematology Monographs and Perspectives 6, 529 pp. Brill Leiden-Boston, The Netherlands-USA.

De Waele E., Loots G.C., Heyns J. 1988. Observations on the effect of maize root on the hatching of Pratylenchus zeae eggs. Phytophylactica 21: 201-203.

Di Vito M., Zacchero G., Catalano F. 2000. Effect of Pratylenchus neglectus and P. thornei on the growth of faba been. Nematologia Mediterranea 28: 261-265.

Kornobis S. 1982. Badania nad nicieniami-pasożytami roślin wyższych stowarzyszonymi z objawami zahamowania wzrostu roślin kukurydzy w Wielkopolsce. [Investigations on plant parasitic nematodes associated with poor growth of maize in Wielkopolska (Great Poland)]. Prace Naukowe Instytutu Ochrony Roślin 24 (1): 91-128.

Kumari S. 2012. Pratylenchus neglectus (Nematoda: Pratylenchidae) under the rhizosphere of Brassica napus. Helminthologia 49 (2): 92-95. DOI: 10.2478/s11687-021-0019-9.

Meyer A.J. 1985. Mass culture of Pratylenchus zeae (Nematoda: Pratylenchinae) on excised corn roots growing on sterile nutrient agar. Phytophylactica 16 (4): 259-261.

Mizukubo T., Adachi H. 1997. Effect of temperature on Pratylenchus penetrans development. Journal of Nematology 29 (3): $306-314$.

Piszczek J., Mrówczyński M. 2012. Metodyka integrowanej ochrony buraka cukrowego i pastewnego. Instytut Ochrony Roślin - Państwowy Instytut Badawczy, Poznań, 124 ss.

Porter M.J., Vanstone V.A., Davies K.A., Kirkegaard J.A., Rathjen A.J. 1999. Reduced susceptibility of Brassica napus to Pratylenchus neglectus in plants with elevated root levels of 2-phenyletyl glucosinolate. Journal of Nematology 31 (3): 291-298.

Seinhorst J.W. 1970. Dynamics of populations of plant parasitic nematodes. Annual Review of Phytopathology 8: 131-156. DOI: 10.1146/annurev.py.08.090170.001023.

Talatschian P. 1974. Development of populations of phytoparasitic nematodes on catch crops with special consideration of oil radish. Zeitschrift für Pflanzenkrankheiten and Pflantzenschutz 81: 538-549.

Tylor S.P., Hollaway G.J., Hunt C. 2000. Effect of field crops on population densities of Pratylenchus neglectus and Pratylenchus thornei in Southeastern Australia. Part 1: P. neglectus. Journal of Nematology 32 (4S): 591-599.

Van Bezooijen J. 2006. Methods and Techniques for Nematology. Wageningen University Plant Sciences, Wageningen, 112 pp.

Webb R.M. 1990. Effects of the nematode Pratylenchus fallax on roots of oilseed rape (Brassica napus var. oleifera). Revue de Nématologie 13 (1): 115-117.

Webb R.M. 1996. In vitro studies on six species of Pratylenchus (Nematoda: Pratylenchidae) on four cultivars of oilseed rape Brassica napus var. oleifera. Nematologica 42 (1): 89-95.

Wolny S. 1990. Materiały do znajomości nicieni-pasożytów roślin stowarzyszonych z objawami zahamowania wzrostu roślin rzepaku ozimego w Wielkopolsce. [Plant parasitic nematodes associated with poor growth of winter rape in the Wielkopolska region]. Prace Naukowe Instytutu Ochrony Roślin 32 (1): 85-92.

Wu H.Y., Tsay T.T., Lin Y.Y. 2002. Identification and biological study of Pratylenchus spp. isolated from the crops in Taiwan. Plant Pathology Bulletin 11: 123-136.

www.fao.org

www.stat.gov.pl 